\title{
Endocrine disruptors from the environment affecting breast cancer (Review)
}

\author{
GLORIA M. CALAF ${ }^{1,2}$, RICHARD PONCE-CUSI ${ }^{1}$, FRANCISCO AGUAYO $^{3,4}$, \\ JUAN P. MUÑOZ ${ }^{1}$ and TAMMY C. BLEAK ${ }^{1}$
}

\begin{abstract}
${ }^{1}$ Instituto de Alta Investigación, Universidad de Tarapacá, Arica 1000000, Chile; ${ }^{2}$ Center for Radiological Research, Columbia University Medical Center, New York, NY 10032, USA; ${ }^{3}$ Programa de Virología, Instituto de Ciencias Biomédicas, Facultad de Medicina; ${ }^{4}$ Advanced Center for Chronic Diseases (ACCDiS), Universidad de Chile, Santiago 8380000, Chile
\end{abstract}

Received October 16, 2019; Accepted February 10, 2020

DOI: 10.3892/ol.2020.11566

\begin{abstract}
Evaluation of carcinogenic substances from the environment is a challenge for scientists. Recently, a novel approach based on 10 key characteristics of human carcinogens classified by the International Agency for Research on Cancer (IARC) has emerged. Carcinogenesis depends on different mechanisms and factors, including genetic, infectious (bacteria, viruses) and environmental (chemicals) factors. Endocrine disruptors are exogenous chemicals that can interfere and impair the function of the endocrine system due to their interaction with estrogen receptors or their estrogen signaling pathways inducing adverse effects in the normal mammary development, originating cancer. They are heterogeneous chemicals and include numerous synthetic substances used worldwide in agriculture, industry and consumer products. The most common are plasticizers, such as bisphenol A (BPA), pesticides, such as dichlorodiphenyltrichloroethane, and polychlorinated biphenyls (PCBs). Xenoestrogens appear to serve an important role in the increased incidence of breast cancer in the United States and numerous other countries. Several studies have demonstrated the role of organochlorine xenoestrogens in breast cancer. Therefore, the overall cumulative exposure of women to estrogens results in an increased risk for this type of cancer. Factors like lifestyle and diet also serve a role in the increased incidence of this disease. The aim of the present study was to analyze these chemical compounds based on the key characteristics given by the IARC, with a special focus on breast cancer, to establish whether these compounds are carcinogens, and to create a model for future analysis of other endocrine disruptors.
\end{abstract}

Correspondence to: Dr Gloria M. Calaf, Instituto de Alta Investigación, Universidad de Tarapacá, Calle Antofagasta 1520, Arica 1000000 , Chile

E-mail: gmc24@cumc.columbia.edu

Key words: endocrine disruptors, bisphenol A, dichlorodiphenyltrichloroethane, polychlorinated biphenyls, cancer

\section{Contents}

1. Introduction

2. Data collection method

3. Bisphenol A (BPA)

4. Dichlorodiphenyltrichloroethane (DDT)

5. Polychlorinated biphenyls (PCBs)

6. Conclusions and future perspectives

\section{Introduction}

Carcinogenesis is a result of an extended process that depends on a variety of different mechanisms and factors as genetic, infectious (bacteria, viruses) and environmental (chemicals) (1). Nowadays, some chemicals agents are fundamental in our everyday life and contribute to simplifying our daily activities. However, it is well-known that long-lasting exposure can be harmful to humans. For many years a proper evaluation of these substances and their classification as a carcinogen has been an issue and a challenge for scientists (2). International agencies have been aware of this matter, thus, the International Agency for Research on Cancer (IARC), with a group of experts, has introduced a new approach for analyzing carcinogens. They agreed on a classification based on 10 common characteristics of these agents regarding their mechanistic information $(3,4)$. Therefore, providing a more reliable way to deal with that evaluation difficulty. After a debate, they concluded that a chemical compound that exhibits more than one of these characteristics must be sufficient to be considered as a carcinogenic agent to humans, ergo belonging to group 1 according to the IARC. Although many environmental compounds have been evaluated according to the IARC classification there are still many unclassified. To know whether those compounds are or not carcinogenic to humans will open a vast possibility for policymakers, governments, scientists and the industry to implement and look for new compounds less harmful to living organisms including humans. Regarding environmental compounds to be evaluated, we focused on those known as endocrine disruptors chemicals (EDCs), due to their relevance in breast cancer. 
As a general statement, endocrine disruptors are chemical compounds mainly derived from industrial manufacture that can interfere with the normal function of the endocrine system (5). Most of these chemicals are widely used in agriculture, industry and many consumer products. Principally, their effects are due to their interaction with endocrine receptors, such as estrogen receptors (ERs) or alteration of their signaling pathways (6); therefore, they can interfere with the normal development and function of a certain organ affecting the normal cell growth (7). Some plasticizers such as bisphenol A (BPA), pesticides as dichlorodiphenyltrichloroethane (DDT) and polychlorinated biphenyls (PCBs) (8) are well-known endocrine disruptor and a proper assessment will give more insight regarding their carcinogenic properties.

It is well known that estrogen is one of the key hormones required in puberty and that is crucial for sexual differentiation. Besides, taking into account that most of the environmental chemicals, called estrogen disruptors or xenoestrogens, are environmental pollutants and at the same time are hormonal modulators (estrogen/androgen); and that they can dysregulate hypothalamic-pituitary-gonadal axis potentially either inducing reproductive disorders or cancer; thus, the evaluation of endocrine disruptors and understanding of their biological effects is crucial. Strikingly, the structural similarity of estrogen disruptors with estrogen allows them to bind and activate estrogen receptors and show a similar response even in their absence, which can lead to precocious puberty or cancer signs $(8,9)$.

Xenoestrogens seem to play an important role in the increased incidence of breast cancer in the United States and many other countries $(10,11)$. Several studies have demonstrated the role of organochlorine xenoestrogens in breast cancer. Thus, the overall cumulative exposure of women to estrogens results in an increased risk for this type of cancer, including risk factors as age at menarche, age at first birth, age at natural menopause, parity, and obesity (postmenopausal) (12). Other factors as lifestyle and diet also play a role in the increased incidence of this disease in Oriental women (low incidence) who migrate to the United States (13). Davis and co-workers $(10,11)$ hypothesized that changes in exposures to xenoestrogenic substances might partly account for recent trends in breast cancer.

Most known EDCs have estrogenic and/or anti-androgenic actions and just only a few have androgenic or anti-estrogenic effects. Thus, it appears plausible that they interfere with the normal onset of puberty or in another stage of hormone-dependent growth. Therefore, disruption of that system by exposure to environmental hormone-mimicking substances (i.e., endocrine disruptors) may affect profoundly the normal development. Hormone-like effects involved different aspects of human health, such as alteration of male and female reproductive organs, immune and nervous system alteration, metabolism and obesity manifestation arising cancer risk (14-19). Despite some doubts concerning the direct influence of EDCs on certain hormone-dependent cancers as breast, prostate, ovaries or testicular cancers, it is clear that disruption of the normal endocrine function can cause long-term effects not only in initiation but also in cancer progression. There are several case reports of accidental exposure to estrogenic compounds in cosmetic products, food, and pharmaceuticals correlated with the outbreak of epidemics of premature thelarche in some geographical areas that have also been suggested to be linked to exposure to estrogen disruptors (8).

Estrogen-like EDCs are abundantly in our environment including DDT, dioxin, PCBs, and BPA. These are exogenous, men-made chemicals found in various plastic products, flame-retardants, pesticides and many other products used on a daily basis $(8,9,20)$. In general, some of the major effects of EDCs are on puberty, a period of rapid physiological changes like a growth spurt, maturation of the gonads and the brain, affecting the normal function of the endocrine system and causing various health defects by interfering with the synthesis, metabolism, and cellular responses of natural estrogens. In particular, the widespread presence of EDCs is suspected to contribute to the trend of earlier pubertal onset. In addition, fetus development, another phase of rapid cellular growth is also greatly affected. Factors regulating the physiological onset of puberty or mammary gland development in utero upon environmental pollutants are complex and poorly understood, thus hampering investigation of the possible role of environmental pollutants and cancer inductors (9).

\section{Data collection methods}

For this review article, a thorough search on MEDLINE (through PubMed), Web of Science, and SCOPUS was performed, from inception to March 2019, in order to identify studies addressing the association between BPA, DDT, PCBs and the 10 key characteristics of known human carcinogens provided by IARC (4).

\section{Bisphenol A (BPA)}

BPA is a synthetic-chemical substance present in several consumer goods that are daily used. It is applied to manufactured plastic bottles, epoxy resins for metal food and drink cans, dental sealants and thermal paper production. The main route by which humans are exposed to BPA is via oral consumption, that is, contaminated drinks and food resulted from high heat or physical manipulation of these products (21). In the USA approximately $95 \%$ of the population has high levels of BPA in urine (22). Sorely, this compound has been related to human cancer. It has been reported that high levels of BPA in humans increase breast cancer risk since it acts as an estrogen-like interacting with the estrogen receptor- $\alpha$ $(\mathrm{ER} \alpha)(23)$, therefore, inducing cell proliferation by reducing apoptosis rate (24) and changing gene expression with low breast cancer prognosis (25).

BPA alters cell proliferation, cell death, or nutrient supply. Several data demonstrate the effect of BPA on cell proliferation. There are some epidemiological studies that have shown a correlation between BPA exposure and human cancers (26). Authors (27) demonstrated that rats exposed to BPA in their prenatal stage had their mammary gland signaling pathways associated with the cell cycle, the developmental processes, apoptosis, and metabolism altered. On the other hand, the exposure to BPA in the early stages of uterine development is fundamental in the increase of risk cancer $(26,28,29)$ and the susceptibility for cancer progression (27). 
Other approaches in vitro indicated that BPA stimulated growth in an estrogen-dependent manner in breast cancer tissues (30). An interesting study evidenced that exogenous hormone-like compounds or phytohormones exhibited similar gene profiles to the endogenous hormone estradiol, crucial for cell growth at initial phases of development (31). Moreover, epigenetics and genetics modifications are observed in epithelial cells affecting at a certain level the normal cell growth (30). To know more in detail regarding the biological effects of BPA upon mammary gland, a study of gene expression profile has been made, indicating that a high dose of this chemical induces changes in genes related to differentiation, proliferation, immune system, growth, and stress suggesting adverse effects on developmental processes in the mammary gland (32). In addition, modification of proliferation and gene expression was also observed in human ovarian cancer cells when they were exposed to environmental BPA concentrations (33). Despite all this evidence, the current knowledge regarding the molecular mechanisms by which BPA acts is not enough and further studies are necessary to understand more in detail the specific signaling involved in each type of cancer since each one has its own mechanism of action (34).

The effects of prenatal exposure to BPA on the rat mammary gland at different ages of development were studied and data indicated that exposure to this xenobiotic induced subtle but important modifications on the mammary gland that were dose-and time-dependant and it affected the susceptibility of the gland to transformation $(28,32,35)$. BPA exposure induced changes in the number of the most undifferentiated epithelial structures (TEB and TD), together with modifications in the expression of several genes at different ages, long after the end of the exposure. Furthermore, the low dose also modified the gene expression profile of the gland as a function of age $(28,32,35)$. The higher susceptibility of TEB to neoplastic transformation was attributed to the fact that this was composed of the active proliferating epithelium (36). Thus, results suggested important modifications in the morphology of the mammary gland as an increase in the number of the structures that were a target for carcinogens and had an effect on breast cancer susceptibility later in life (36-38). Authors (39-41) postulated that the mechanism of pregnancy-induced protection was mediated by the induction of mammary gland differentiation driven by the hormonal milieu of pregnancy, which created a specific genomic signature in the mammary gland that made this organ permanently refractory to carcinogenesis. Hence, they used parameters related to differentiation and proliferation activity as markers to assess modifications in the susceptibility induced carcinogenesis by the effect of BPA exposure. On the other hand, the protective effect of parity seemed to be caused by persistent changes in circulating hormones or growth factors rather than local effects on the mammary gland $(42,43)$. Other authors $(44,45)$ proposed that the changes occurring in the mammary gland that affected its resistance to transformation occurred during the process of involution that followed pregnancy and lactation by eliminating pre-malignant cells or cells that were particularly susceptible to oncogenic transformation, thus avoiding the progression to an invasive state. This interesting hypothesis was not radically different from the one first proposed by $\mathrm{Hu}$ et al (46) who postulated that the Lob 1 and the TEB found in the breast of nulliparous women or of young virgin rats respectively, did not completed their differentiation into Lob 2, Lob 3, and Lob 4, then BPA exposure induced changes in the mammary gland that were time- and dose-specific. Prenatal exposure to the non-steroidal estrogen diethylstilbestrol has been associated with increased breast cancer risk (47), whereas neonatal exposure reduced the incidence of spontaneous (48) and induced mammary tumors $(49,50)$. Thus, exposure to estrogenic compounds, especially in utero, acting as endocrine-disrupting chemicals might have potential adverse effects on hormone-sensitive organs such as the breast (32).

$B P A$ is genotoxic. Although different international organizations, regulatory entities, and manufacturing industries have been involved in the discussion regarding BPA there are still some concerns about its genotoxicity and human safety (51). It has been shown that BPA produces reactive oxygen species (ROS) affecting the normal functioning of mitochondria, causing DNA damage and changing the expression of some genes due to DNA methylation (52). Particularly, genotoxic effects have been observed in ER $\alpha$-negative mammary cells, where nanomolar concentrations of BPA are enough to exhibit proliferative effects. The molecular mechanism at low-doses of BPA involves the up-regulation of c-Myc and other proteins associated with cell-cycle in mammary cells, eventually inducing cell proliferation $(53,54)$.

BPA modulates receptor-mediated effects. As it was mentioned before, BPA is known as an endocrine disruptor due to its capacity to alter the endocrine system function. For instance, it has been reported that at micromolar doses BPA has a considerable affinity for ER when it is compared with other phenol compounds. Besides, in MCF7 cell line studies it has been proven that BPA induces proteins that are regulated by estrogen, therefore mimicking $17 \beta$-estradiol (E2) but not only in vitro but also in vivo, being considered for some authors as an agonist for this hormone (55). Structurally speaking it is possible to say that the ER form a hydrophobic pocket were this diphenylmethane can be docked in a non-coplanar manner, consequently, the endogenous ligand does not have access. Therefore, it has been proposed that BPA can serve as an allosteric modulator. Interestingly, this interference does not only affect the binding with the estrogen but also affects the communication between the ligand-binding domain (LBD) and the DNA binding domain (DBD) (56).

Others (23) reported the effects of BPA and BP -another structurally similar estrogenic ligand- on critical physiological responses such as growth and apoptosis in breast cancer cells. The same authors also reported that small differences in the shape of the complex ligand-ER $\alpha$ had a stronger effect on estrogen-induced apoptosis than replication induced by estrogen in breast cancer cells. Due to their structural compositions, some bisphenol derivatives such as bisphenol-S (BPS) and bisphenol-F (BPF) have been used to replace BPA. Unfortunately, it has been demonstrated that similarly to their analog they exert some cancer progression properties as well. By the study of protein expression, migration and proliferation it was determined that these compounds were involved in the ER-dependent pathway, likewise, BPA, mimicking endogenous estrogen (57). Thus, cells under BPA treatment gained 
mesenchymal phenotypes via the epithelial-mesenchymal transition process (EMT) with further migration potential. Regarding E2, it has been demonstrated that physiological concentrations of E2 along with a low dose of BPA $\left(10^{-9} \mathrm{~mol} / \mathrm{l}\right)$ can decrease the apoptosis rate (24). Therefore, supporting the fact the BPA can indeed modify the receptor-mediated effects but also affects the biological result of the endogenous ligand. As mentioned before, BPA causes a conformational change of the receptor and this can be also done by other compounds such as synthetic estrogen, diethylstilbestrol that through steric and electrostatic features can alter the structure of the estrogen receptor. Moreover, this modification results in an alteration of gene expression even though BPA can evenly interact with $\mathrm{ER} \alpha$ and $\operatorname{ER} \beta$ (58).

Nevertheless, it is important to take into account the route of administration since BPA is metabolized preferentially in the liver via glucoronidation. Therefore, its response may vary depending on the type of exposure, dose, duration, as well as the stage in life when it occurred (59). Thus, many studies have mainly demonstrated the importance during fetal exposure, since BPA can cause severe and long-lasting effects such as abnormal reproductive organs and a significant increase in pre-neoplastic lesions, and intraductal proliferation contributing to cancer formation $(60,61)$. On the other hand, it has been shown that ERs are also located at extranuclear-sites, such as membrane or cytosol, activating other than the classical transcription via estrogen receptor elements (EREs). Even more surprisingly, it is the fact that this outside-nucleus-activation can induce other signaling molecules exerting gene expression as well, making active other endocrine receptors such as G-coupled protein receptors, estrogen-related receptor gamma, and thyroid receptors (62).

BPA is immunosuppressive. It is well known that inflammatory responses are important during the early stages of damage. However, when this condition becomes chronic can cause several inflammation-related diseases. Thus, the influence of BPA has been demonstrated on the inflammatory response via alteration of the immune system and through changes in their cells, altering cell proliferation and functioning (63). There are many receptors involved in the immunity response, for example, ERs, which are closely related to the such system since it has been shown their influence to mediate their response. Likewise, BPA can bind to other receptors relevant in the immune system response such as aryl-hydrocarbon receptor (AhR), Toll-like receptors (TLRs) and peroxisome proliferator-activated receptor (PPAR) affecting, directly and indirectly, the response (63-66).

Noticeably, the relationship between BPA and ERs affects the immune system and the inflammatory response, presumably linked via cross-talking. It has been shown that activation of ERs can modulate the type 1 helper cell immunity and type 2 helper (Th1)/(Th2) ratio (67). Naturally, the presence and the effect to exert will depend on physiological and pathological conditions, stage of development of the immune system, type of cell, and dose/time of exposure to BPA. Even though BPA is a recognized EDC, the study of these effects largely depends on the dose/concentration, exposure period, clearance and metabolism, sample source, and adult or pre-perinatal exposure among others (68).
BPA alters DNA repair or causes genomic instability. Ligand-receptor interaction is a complex process that brings out a sophisticated network of communication with a wide spectrum of effects. Interestingly, this cross-communication can occur at different places of the target cell. For instance, beyond the classical ER genomic pathway, steroids can also elicit a rapid non-genomic cascade via secondary signaling pathways due to its subtype or receptor localized in the membrane, therefore activating the mitogen-activated protein kinase MAPK cascade (69). The mitogen-activated protein kinase is in turn related to different mitogens and oncogenes enlarging the spectrum of interactions to eventually modulate DNA sequences related to proliferation or even anti-apoptotic processes (69).

Even though upstream mediators like Ras or Src are complex to analyze due to their multiple interactions it has been proved that only following MAPK pathway is enough to demonstrate the effects on DNA, particularly chromosome alteration, demonstrated via induction of Ras overexpression with a subsequent increase of micronucleus frequency (sign of DNA damage) (70). Similarly, BPA can trigger the same responses due to its versatility. Interacting with ERs, this EDC activates the non-genomic route such as phosphorylation of Erk1/Erk2 (71), thus affecting the phosphorylation state of subsequent mediators to finally alter the gene transcription or DNA stability as described above.

BPA induces epigenetic alterations. An epigenetic alteration is an inherited non-genomic alteration. It can involve DNA hypermethylation/hypomethylation, histone post-translational modifications (acetylation, methylation, phosphorylation, ubiquitination and ADP ribosylation) and other regulatory mechanisms such as expression of non-coding RNAs (ncRNAs) (72,73). All these are indeed fundamental in the early stages of development such as a perinatal period. Briefly, the DNA methylation is normally related to modulation in gene promoters (repression) and is mainly present in the $\mathrm{CpG}$ dinucleotide sequence (74). Regarding the histone post-translational modification, it refers to modifications that affect the histone structure with further DNA-access-difficulties, thus changing the expression of certain genes. The ncRNAs are another kind of inheritable regulator which acts at mRNA level triggering degradation or translation inhibition (75).

For these epigenetic changes to be inherited they must occur at early phases of the prenatal development, particularly during the programming and reprogramming gene expression and it is evident that any environmental contaminant will have a tremendous effect on the proper cellular growth and for future generations. As mentioned before, BPA can be a ligand for ERs, causing many effects at different levels that seem to be linked to epigenetic changes that may be one of the plausible molecular mechanisms (76,77). Epigenetic effects have been studied over the last decade and many environmental factors have been published. For instance, Morgan et al (78) in 1999 studied the influence of epigenetic modification on the offspring phenotype, being a change that can be transferred to another generation. An interesting study showed that maternal exposure to BPA significantly changed the coat color of the agouti $\left(\mathrm{A}^{\mathrm{vy}}\right)$ mouse offspring due to the hypomethylation in the 
cytosine-guanine $(\mathrm{CpG})$ dinucleotide sites within the Agouti gene, especially, in the intracisternal A particle. Remarkably, this effect was reverted by changing the maternal dietary, providing a source of the methyl group via folic acid supplementation (79).

Molecular effects can also be caused by exogenous estrogen compounds since it has been shown that exposure to BPA, as well as, low doses of estradiol can cause important effects such as the modulation of cell cycle or apoptosis via epigenetics mechanisms and even increasing the cancer risk in the adult period. It has been suggested that neonatal exposure to BPA or other estrogen-like compounds induces hypomethylation of phosphodiesterase type 4 variant 4 (PDE4D4) repressor genes, eventually causing prostate carcinogenesis $(72,73)$. Likewise, early and long-term exposure to low doses of BPA increases the susceptibility of breast neoplasm in adults. It is postulated that this long-term exposure also may induce a ligand-independent response. However, the mechanisms by which the effects of BPA exposure are transferred onto the offspring are still not well known. More than 100 genes have been related to tumorigenesis, which under the influence of BPA can modulate the tumorigenesis. For instance, the lysosomal-associated membrane protein 3 (LAMP3) is hypermethylated under BPA exposure in $\mathrm{CpG}$ island, therefore, reducing the expression. This heritable influence on gene expression was observed in ER $\alpha$ positive breast tumor as well (74).

BPA affects histones by increasing the expression of the histone methyltransferase. A study done in MCF7 cells linked the histone modification to breast cancer risk in animals, particularly, the expression of histone methyltransferase, Zeste Homolog 2 (EZH2) in mice exposed to BPA and diethylstilbestrol (DES), another EDC, these changes are modulated by DNA methylation and histone structure modification. These modifications on EZH2 are associated with mammary tissue/gland alterations increasing the risk of breast cancer later as adults $(80,81)$.

BPA induces oxidative stress. Oxidative stress has been related to aging and other degenerative diseases including cancer. ROS are produced by biochemical reactions and they are extensively affected by exogenous factors (82). These reactive species affect different organs and can interact, unfortunately, with several biomolecules. In this context, the most important interaction is with the DNA, forming DNA-protein interactions. Particularly, via 8 hydroxylation on the C-8 position of deoxyguanosine. Therefore, in order to repair this damage, 8-hydroxy-deoxyguanosine (8-OH-dG) is produced indicating a DNA repair product. Thus, under BPA exposition, the (8-OH-dG) can be considered as an oxidative stress biomarker and as an index of DNA oxidation by hydroxyl radical on the C-8 position of deoxyguanosine (83). In vitro studies have demonstrated an important change in the normal balance of antioxidant species such as glutathione when micro molar BPA concentrations are used (84).

In summary, despite years of investigation and the accumulation of results there still are some factors that must be probe and considered to clarify the real effect of BPA in humans. Most of the studies have focused on in vitro approaches. As we mentioned above, BPA has been involved in many interactions with nuclear receptors as well as extranuclear receptors. Therefore, several pathways are activated but the molecular mechanisms are not understood $(85,86)$. Moreover, dose-response, direct-effect measure, route of exposition, cellular surrounding, cell type, organ affected and metabolism are just a few of the factors that must be considered and included in order to get a better insight of the physiologic, toxic, and carcinogenic effects of BPA in vivo and in epidemiological studies $(8,87)$. Therefore, the lack of evidence in experimental animals and deficient epidemiological data regarding its carcinogenicity in humans denote a need for more research concerning BPA exposure and its effects in order to obtain more knowledge to compare and establish some models that will eventually enable us to understand BPA interactions and their biological consequences.

\section{Dichlorodiphenyltrichloroethane (DDT)}

DDT, 1,1,1-trichloro-2,2-bis( $p$-chlorophenyl)ethane, is a synthetic pesticide widely used for disease-vector control and agriculture since the 1940s. It was an important substance in malaria eradication but it was banned in the USA in 1972 and was only allowed to be used in public health emergencies; however, it is still largely used in developing countries for insect control (88). Technically, it is composed of $p, p^{\prime}$-DDT; $o, p^{\prime}$-DDT and $o, o^{\prime}$-DDT forms. It is possible to find its main metabolite, DDE (dichlorodiphenyldichloroethylene), as an environmental contaminant as well (88). Human main-route of exposure is by direct contact or inhalation in those areas where this pesticide is still under use. Nevertheless, due to its chemical features, this compound is highly volatile and extensively spread. Since its onset, it has been deposited into the land or the water, even more surprisingly, it has been found in animals living thousands of kilometers away from the source of contamination due to its long-time-biodegrading process $(88,89)$, it is known that both DDT and its main metabolite (DDE) have a half-life in humans of $>5$ years (90). However, in those countries where this product has been banned the principal route of exposure is by ingesting contaminated food, mainly meat, whereas the risk for nursing infants delivery may be related to maternal DDT levels, plus the environmental exposure to the pesticide (91). DTT is bio-accumulated in the lipid component of biological systems with a slowly released into the bloodstream since it is highly lipophilic and resistant to degradation. Its metabolites have been associated with metabolic syndrome by interfering with the weight control process and with carcinogenicity and other diseases such as type 2 diabetes mellitus (92-95). Besides, reports have shown that DTT is able to bind the ER, therefore, affecting all receptor-mediated changes such as stimulation of breast cancer cells to proliferate (96-98).

DDT alters cell proliferation, cell death, or nutrient supply. From studies evaluating the effects of $o, p^{\prime}$-dichlorodiphenyltrichloroethane (o,p'-DDT), and its metabolites p,p'-dichlorodiphenyldichloroethylene (p,p'-DDE), and p,p'-dichlorodiphenyldichloroethane (p,p'-DDD), it is possible to mention that these compounds can modulate many carcinogenesis-related processes, including breast cancer, underlining the relevance of persistent organic pollutants in the environment. Concerning the invasive potential, DDT decreased cell viability in the less invasive MCF-7 
cell line. However, no evident response was observed in treated-MDA-MB-231, being the most invasive cell line (99). Acting through natural hormone pathways they can affect the synthesis, metabolism, transport, or alter the hormone-receptor binding (99). In addition, they can interact with the aryl hydrocarbon receptor (AhR) altering the expression of enzymes such as CYPP450. Thus, promoting cell growth and contributing to abnormal physiological responses for further development and progression of cancer (100). However, more epidemiological studies are required in order to establish a direct relation between DTT and its long-term effects on carcinogenesis.

DDT is genotoxic. A few years ago and despite the efforts, results from studies trying to determine whether DDT caused genotoxic effects were divergent. The cytogenetic effect of DDT was investigated in human blood cultures in vitro, and although there was no correlation between DDT concentrations and chromosomal aberrations in cells, statistics showed that at certain DDT concentrations $(0.20,4.05$, and $8.72 \mathrm{mg} / \mathrm{ml})$ the proportion of cells with structural aberrations was significantly higher in respect to the controls (101). Some in vivo studies have provided more data related to the genotoxicity of DDT throughout the years. For instance, a study done in mice indicated that after $24 \mathrm{~h}$ of DDT injection the chromosomal aberrations reached its maximum percentage (102). Thereafter, it was described that DNA damage was among the effects caused by DDT and its metabolites, which was demonstrated in both, in vitro and in vivo studies including human and non-human test systems (88). Nevertheless, is possible to say that there still some unexplained mechanisms involved in human carcinogenesis related to DDT.

DDT modulates receptor-mediated effects. Pesticides, including DTT and its metabolites, have demonstrated their estrogenic activity in both in vivo and in vitro studies. Several lines of evidence have investigated whether DDT or its metabolites affect breast cancer risk. Those studies included the identification of some congeners of DDT as environmental estrogens. This action is due to the competition of these compounds with the endogenous hormone, E2 for the receptor (103). Moreover, it has been published that DTT can modulate the metabolism of the estrogen and other key elements taking part in breast cancer development $(104,105)$. Some metabolic essays have shown that DDT can also inhibit metabolic cooperation between cells, modifying the function of the cells (106). However, due to limited evidence is not possible to relate this compound (DDT) as a direct promoter of mammary tumors and as an inhibitor of gap junctional intercellular communication (107).

To have a clear scenario regarding the DDT-ER interaction in breast cancer or another cancer etiology is fundamental to understand the molecular biology, this could also explain the risk of breast cancer and how other estrogenic compounds can modulate the effects of endogenous estrogen in cells and tissues. To elucidate how estrogenic compounds can compete with DDT by their estrogenic potential $(108,109)$ some studies have yielded several molecular mechanisms explaining this interaction. For instance, it has been shown that DTT increased the growth of HTB 133 cells by enhancing the ER-DNA specific binding to the specific ERE (estrogen response elements) and also potentiates the activity of cyclin-dependent kinase 2 in MCF-7 breast cancer cells but not ER-negative HTB 125 breast cells or rat liver epithelial cells (110). Besides, there is evidence in vivo and in vitro that shows the influence of DTT in the interaction of ER and specific genes promoting cell proliferation $(11,109)$, in fact, DTT can also bind to ERs in different places of the body other than female reproductive sites. The knowledge of a $\beta$-receptor has introduced a new understanding of estrogen and DDT binding. Considering these concepts one can understand, partly, the molecular actions of DDT and its relation with ERs (108).

At the same time, epidemiologic studies have assessed the link between environmental exposure to DDT and the increased risk of cancer; however, the data is not fully consistent to establish a positive and direct association (111). Many factors are involved and have exerted an important role in the cancer development, particularly in the breast cancer, such as age, breastfeeding history, hormone therapy, evidence of breast cancer in the family, radiation exposure, presence/absence of gene mutations being without any doubt lifestyle is one of the most important factors (109). Accordingly, there are some controversial results regarding the correlation between DDT/DDE and the risk and developments of breast cancer $(112,113)$. Even though there are some limitations in epidemiological studies, we cannot deny from this knowledge, the fact that exposure to environmental contaminants will cause a detriment in the system of living organisms in the future. Therefore, the need for more studies to determine the biological effects of DTT is evident, involving molecular mechanisms and more solid epidemiological studies.

DDT is immunosuppressive. Regarding the effects of DTT on the immune response, it is possible to find data from decades ago. Street and Sharma (114) studied the dose-dependent relation between DDT and immunosuppressive effects in mammals. Supporting previous works, they established that DDT could alter the metabolism of antibodies exerting a suppressive effect upon the immune system. Particularly, they found out that the antigen-induced increase in serum $\gamma$-globulin was later decreased with DDT treatments (114). This immune-mediated effect by DDT could also imply a risk in breast cancer (115). Strikingly, other epidemiological approaches demonstrated some relation between DDT exposure and impaired immune response, thus facilitating infections or noxious vectors related to a certain type of cancer as lymphoma (116).

DDT induces epigenetic alterations. As aforementioned, epigenetic modifications such as DNA methylation, histone modifications, and microRNAs are heritable changes that involve, predominantly, DNA methylation and histone modifications (117). In addition, miRNA are other gene modulators that have a relation with epigenetic processes and carcinogenesis (118). It has been demonstrated that exposure to DDT and its binding to ER may induce transcriptional effects. Furthermore, this exposure, at the hypothalamus level, is related to oxidative stress in young male rats that by epigenetic alteration can alter ER function as well (119). An in vivo study performed in rats examined the effects of DDT for over three generations. Results showed that this pesticide has the ability to induce epigenetic trans-generational inheritance for obesity 
and related diseases (120). This is fundamental to understand the effects of DDT long-term exposure on humans.

Another change that DDT can cause at the epigenetic level is the expression of miRNAs. The characterization of miRNA can vary depending on the type of tissue or cells that are analyzed (121). A study performed in rodents showed a significant positive modulation of miRNA in hepatic cells. Therefore, it is viable to state that DTT may modulate miRNA for those genes involved in detoxification, such as genes that encode for CYP enzymes. It has been postulated that a plausible mechanism is DNA methylation (121). The available scientific tools, of the modern world, have allowed us to get acceptable evidence of the long-term exposure to DTT and its effects on the biological system. However, we certainly know that more investigation must continue regarding the direct epigenetic effects of DDT in order to get a better insight into the molecular mechanisms involved.

DDT induces oxidative stress. Some studies have demonstrated that several organochlorine pesticides (OCPs) including DDT can induce CYP enzymatic complex. It is well-known that cytochromes $\mathrm{P} 450$ are in charge of detoxification of exogenous compounds with a subsequent formation of metabolites, which can be active and exert a carcinogenic action (122). Besides, most of the OCPs are able to produce ROS (123-125). It has been shown that OCPs can induce oxidative stress and lipid peroxidation in various tissues $(126,127)$, and that oxidative cycle by the effect of pesticides can cause structural damage to DNA (128). Additional studies have evaluated DDT exposure on mammary gland and hepatic cells in rodents, determining ROS production. Therefore, these studies rely on this fact to explain the oxidative DNA damage $(129,130)$, and this is an important step in the process of carcinogenesis.

DTT induces chronic inflammation. Interestingly, data show the effects of DTT upon inflammation since it is widely known that macrophages are involved in inflammatory responses (131). It has particularly been shown that nitric oxide (NO) production and pro-inflammatory cytokines are increased in mouse macrophages in a dose-dependent manner by DTT via NF- $\mathrm{BB}$ even more, modulating the inducible nitric oxide synthase (iNOS) gene expression (131). But NO is not only associated with inflammation but also with increased cancer risk (132). Besides, it is documented that apoptosis is influenced by DDE through the generation of pro-inflammatory mediators (133). Unfortunately, the molecular mechanisms related to all these physiological responses are not resolved yet. It is important to notice that pro-inflammatory factors and OCPs can also activate other transcription factors through different signaling pathways. Therefore, further investigation is imperative in this regard to have a clear picture of the mechanism relating to DDT with the inflammatory process.

The role of organochlorine compounds as etiologic agents in breast cancer was suggested by case-control studies that showed that a) levels of DDT and related metabolites (primarily p,p'-DDE) higher in serum or tumors of breast cancer patients versus controls (134), and b) DDE levels higher in mammary adipose tissue of estrogen receptor-positive breast cancer patients compared to controls (111). Overall, the insecticide DDT was classified as 'probably carcinogenic to humans' in group 2A by IARC based on limited evidence in humans since there was a positive association in cancers of the liver, testis, and non-Hodgkin lymphoma (135).

\section{Polychlorinated biphenyls (PCBs)}

PCBs comprise 209 synthetic chemicals distinguished by degree and pattern of chlorination. They are non-flammable and chemically stable. Because of their chemical properties, these compounds have been used worldwide for many industrial purposes such as plasticizers, pigments, capacitors, and transformers among other uses (136). PCBs were used from 1929 until 1979 in the USA (137). Like other synthetic industrial compounds, PCBs are accumulated in soil and water and then taken by animals and eventually by humans. Therefore, the main exposure route is through the food chain (138). Due to high concentration of chlorine compounds its degradation can last for years giving it time to bio-accumulate in the fatty tissue of living organisms and then transferred to other living organisms including humans. For instance, an important accumulation of these compounds was found in breast adipose tissue (139). Other exposure routes are inhalation or drinking water with portions of PCBs that are still remnant (136).

The manufacture of PCBs was banned in the late 1970s in the USA $(137,138)$ and despite the restriction, it is still used for some domestic production or discharged by some industrial manufacturers (136). It was calculated that in 1991 the intake was $<0.001 \mu \mathrm{g} / \mathrm{kg} / \mathrm{day}$ in the USA $(88,140)$. The bio-accumulation of PCBs in human tissue has been associated with pathological effects. High levels of certain PCBs have been observed in breast tissue and characteristics as ubiquity, lipophilic, and accumulation have contributed to breast cancer etiology (141-143). This accumulation is mainly present in fatty tissue due to the high lipophilicity of PCBs and their half-life has been estimated for $>10$ years (144). Unfortunately, the mechanism is not fully understood but it is suggested that some of these PCB compounds can have an effect upon some nuclear receptors such as $E R \alpha / \beta$ or glucocorticoid receptor. Either the agonist or antagonist modulation depends on the structural characteristic of the compound (145). Thus, it does not only exert an estrogen-like activity but also induces enzyme formation such as cytochrome P450 complexes (146). Even though large scale use of PCBs decreased after their prohibition (147), it still exists in the environment (88). As consequence, the intake of the population has not stopped. Sadly, their environmental distribution has no limit and will be circulating for many years in the soil, waters, and animals.

Epidemiological studies in animals and humans support these findings (148). However, more studies are required to understand this relation and the specific action of organochlorine compounds in carcinogenesis. Therefore, PCBs will be assessed according to the key characteristics stated by the IARC-for human carcinogens- (4), and we will explore their bioactivity profiles regarding their potential impact on carcinogenic mechanisms as follows.

PCBs alter cell proliferation and cell death. Considering PCBs as a mixture of polychlorinated biphenyl compounds, the results related to cell proliferation and cell death, obtained from different studies are complex to analyze. Particularly, on 
breast cancer, different outputs make hard to conclude whether PCBs represent a factor for its incidence. It is known that PCB compounds behave as endocrine disruptors $(149,150)$. These environmental contaminants are metabolized by the enzymatic complex so-called CYP450, releasing metabolites which have different performances and effects. Some of them can bind competitively to ERs and other receptors, such as 3, 4-diOH-PCB3 that can have strong effects on the apoptosis process (151). Therefore, it has to be considered that metabolites themselves play an independent role in each process and they must be recognized as individuals for some studies according to the specific process to be assessed. Some authors (152) have been evaluating different PCB metabolites in order to get an insight into their specific role in the cell cycle process, establishing some of them as initiators and promoters of certain cancers (152). For instance, some studies have focussed on the initiation stage of hepatic cancer. Therefore, some specific PCB metabolites including ROS are formed during the metabolic process of PCBs. Such substances eventually will interact with molecules like proteins, RNA and even DNA, causing potential damage specifically in hepatocytes (153). On the other hand, in epidemiologic studies indicated that PCBs certainly aid the survival of those with breast cancer (154), which mechanisms are unknown. Perhaps through their activated metabolites or due to its interaction with the nuclear receptor, these and other specific details must be clarified in further studies.

PCBs are genotoxic. As PCBs consist of a number of isomers and congeners, the study of their genotoxicity requires separate analysis. Several commercial mixtures have been examined in vitro to determine their influence in the promotion and initiation of the tumor $(136,155)$. The metabolism of PCBs by cytochrome $\mathrm{P} 450$ iso-enzymes produces different species depending on the halogenation grade and their position in the molecule (136). It has been noticed that high halogenated compounds induce CYP450 enzymes and low chlorinated biphenyls are easily bio-activated via metabolic processes. Further conversion leads to different adducts via hydroquinone oxidation, which is involved in the DNA bases binding (156), being the main contributor in the genotoxicity and toxicity of PCBs. Specifically, the reaction of the semiquinones or quinones metabolites of PCB with DNA and nucleotides has also been evaluated through segregation by thin-layer chromatography and detected by ${ }^{32} \mathrm{P}$-post-labeling (157). Assays together with other mechanistic studies provide convincing evidence that specific PCB congeners can be bio-transformed to genotoxic, therefore, potential metabolites as initiators in the carcinogenic process (158). Particularly, it is feasible to think that concerning breast cancer most of the origin is attributable in a great manner to ER activation. However, it has been shown a certain grade of DNA damage in negative estrogen-receptor systems. As consequence, it is possible to say that the biotransformation process of some compounds to their active forms as quinones by CYP450 can produce DNA damage, similar to what was described before (159).

PCBs induce epigenetic alterations. Epigenetic alterations are critical at early-life exposure determining a set of alterations consisting of DNA methylation, histone modifications, and non-coding RNAs with alteration of gene expression (160). Such epigenetic changes can even last over generations contributing to the incidence of diseases. PCBs are known for intervening in estrogen normal metabolism and transcription response as endocrine disruptors but also they are known because of their epigenetic-modulator activity, especially, by decreasing DNA methylation of certain promoters and changing histone post-translational levels (160). Another study (161) evaluating the same changes in DNA and histones found that exposure to $\mathrm{PCBs}$ at the early stages of development mostly reduces DNA methylation and histone post-translational modifications. Furthermore, there is an influence upon the androgenic receptor expression, establishing an interesting relationship between some of these modifications and gender (161). A study (162) in utero and post-natal exposing rats to organochlorine pesticides found that PCBs decreased global genome DNA methylation and $\mathrm{CpG}$ methylation of the promoter of the $C D K N 2 A$ (162), which encodes for several proteins, and tumor suppressors most of them. All these studies certainly grant more information serving as hallmarks to understand human cancer (163). An epidemiological study (164) done in a population exposed to low doses of pollutants including PCBs revealed that indeed there is a relationship with the global hypomethylation of the DNA and the concentration of chemical pollutants (164). Nevertheless, it does not rule out other factors that may also influence the degree of epigenetic modifications such as aging, dose, diet, lifestyle, physiological characteristics of each subject, and other chemical exposure that might have contributed to the result.

PCBs induce oxidative stress. Some PCB congeners are metabolized by enzymes (CYP450) resulting in quinones and semiquinones, then reactive electrophiles will eventually form adducts. Studies (165) focused on that concept also have shown that the production of ROS after metabolic reactions of PCBs behaves in a dose-time-depend manner (165). It is well-known that PCBs act as endocrine disruptors, having an estrogenic action defined by their affinity (166). Moreover, it is known that catechol metabolites of E2 induce free radical damage and this damage was detected as DNA strand breaks and the formation of 8-oxodeoxyguanosine (8-oxodG). It was proposed that these arose via a redox cycling mechanism $(159,167,168)$. Attention must be paid when endocrine disruptors are related to carcinogenesis of breast cancer since it was found that PCB exposure affects breast cancer risk and progression via Rho-associated Kinase (ROCK) signaling (169). In a study performed in MDA-MB-231 cancer cells (ER-negative), assessing the effects of PCBs upon migration/invasion it was found that characteristics of metastases were augmented by activating ROCK pathway, which is the main modulator of Rho activity such activation was mediated by ROS species derived of PCB metabolism (169). Therefore, inhibition of ROCK appears to represent a novel therapeutic approach for metastases in breast cancer upon PCB exposure (169). However, it has been observed that metabolized products as hydroxylated $(\mathrm{OH})$ PCB congeners, $(\mathrm{OH})-\mathrm{PCB}$, can distribute differently to their progenitors due to their solubility, therefore, they are able to reach other organs and contribute to other processes such as altering cell cycle via ERK1/2 and contributing to neurotoxicity instead of generating only ROS (166). 
Table I. Summary of the key characteristics obtained for each compound following the evaluation.

\begin{tabular}{|c|c|c|c|}
\hline Key characteristics & $\begin{array}{c}\text { Bisphenol A } \\
\text { (BPA) }\end{array}$ & Dichlorodiphenyltrichloroethane & $\begin{array}{c}\text { Polychlorinated } \\
\text { biphenyl }\end{array}$ \\
\hline It alters cell proliferation, cell death, or nutrient supply & $\mathrm{x}$ & $\mathrm{x}$ & $\mathrm{x}$ \\
\hline It is genotoxic & $\mathrm{x}$ & $\mathrm{x}$ & $\mathrm{x}$ \\
\hline It modulates receptor-mediated effects & $\mathrm{x}$ & $\mathrm{x}$ & - \\
\hline It is immunosuppressive & $\mathrm{x}$ & $\mathrm{X}$ & $\mathrm{x}$ \\
\hline It alters DNA repair or causes genomic instability & $\mathrm{x}$ & - & - \\
\hline It induces epigenetic alterations & $\mathrm{x}$ & $\mathrm{x}$ & $\mathrm{x}$ \\
\hline It induces oxidative stress & $\mathrm{x}$ & $\mathrm{x}$ & $\mathrm{x}$ \\
\hline It is electrophilic or can be metabolically activated & - & - & $\mathrm{x}$ \\
\hline It induces chronic inflammation & - & $\mathrm{x}$ & $\mathrm{x}$ \\
\hline
\end{tabular}

PCBs are electrophilic or can be metabolically activated. Many studies (167,170-172) have demonstrated that lower halogenated biphenyls are found in high amounts in the breast, where they are available for metabolism by cytochrome P450-mediated oxidations within the breast tissue itself, and then those metabolites can react with proteins or form adducts. In an analogous paradigm, the carcinogenicity of the endogenous hormone E2 is attributable to the ability of its catechol metabolites to induce free radical damage as well $(167,170-172)$. Some data also suggest that ER- $\alpha$ status may contribute to the PCB-induced oxidative response in breast cancer cells (173).

PCBs are immunosuppressive. We focused also on PCBs immunomodulation action. Different studies support the relation between certain PCB congeners and their effects upon the immune response (174). Like other environmental pollutants, PCBs exert a wide spectrum of biological effects on humans such as immunotoxicity and even allergic reactions via diminishing $\mathrm{T}$ and B cells (175). Epidemiological studies have also studied the effects of PCBs exposure on the immune system, suggesting that exposure to these pesticides is a risky for certain types of leukemia in children and for non-Hodgkin lymphoma (NHL) in adults. Even though, the specific mechanism is not well defined, it has been suggested that it can be toxic for immune cells among other cell cycle modulations (176).

PCBs cause chronic inflammation. Overall, PCBs can widely affect human health and cardiovascular diseases are not exceptions. There are some data relating these organic pollutants to inflammatory diseases such as hepatic disorders, obesity, and diabetes (177). It has been shown that PCB 126, a dioxin-like pollutant, is one of the most pro-inflammatory compounds in mice, it increases the level of cytokines and pro-inflammatory circulating molecules and it increases the risk for atherosclerosis in a low-fat diet (178). Nevertheless, the evidence that involves PCBs with these inflammatory diseases is still under investigation, since there are other environmental or biological factors not considered yet (179).

In summary, PCBs were classified as 'carcinogenic to humans' in group 1 based on sufficient evidence in humans such as cancer of the breast as well as malignant melanoma with a positive association for non-Hodgkin lymphoma (180).
Regarding the relation with inflammatory-related diseases and chronic inflammation itself, the data are still controversial and deficient. Authors used a cohort of 150 breast cancer patients and 150 control subjects in California and showed that there was not a significant difference in serum organochlorine levels in the two groups (113). Other authors have demonstrated the estrogenic activity of some PCBs and hydroxylated PCBs in breast cancer cells and in the rodent uterus. However, it is also true that other persistent chlorinated pollutants including some PCB congeners, polychlorinated dibenzofurans, and dibenzo-p-dioxins, exhibit antiestrogenic activities in the same bioassay (181). Safe (13) has suggested that in terms of dietary intake of organochlorine pollutants, the overall intake of antiestrogen equivalents was greater than estrogen equivalents in the diet. PCB levels were higher in mammary adipose tissue of breast cancer patients in Connecticut than in controls (182). Education to help patients, health professionals, besides awareness from policymakers and consciousness from the industry are required to diminish the amount of these compounds in the environment. Therefore, more in vivo experiments and epidemiological studies are needed to augment evidence regarding the effects of these endocrine disruptor-compounds in the normal progress of organ formation from critical stages of development upon early- and throughout life exposure. However, data were insufficient for evaluating the alignment of PCBs with the other key characteristics of carcinogens such as DNA-repair alteration, genomic instability, and modulation of receptor-mediated effects

\section{Conclusions and future perspectives}

The evaluation based on the 10 key characteristics of known human carcinogens provided by the IARC has given new approaches to identify carcinogenic risks to humans. In summary, BPA, DDT, and PCBs assessment coincided in five key characteristics of human carcinogens as i) they alter cell proliferation, cell death, or nutrient supply, ii) they are genotoxic, iii) they are immunosuppressive agents, iv) they induce epigenetic alterations, and v) they induce oxidative stress. In addition, both BPA and DDT are able to modulate the receptor-mediated effect. However, DDT and PCBs happen to induce chronic inflammation. Finally, BPA yielded sufficient information as a compound that alters DNA repair or causes 
genomic instability. Table I shows a summary of several signs of carcinogenicity by the effect of endocrine disruptors as a guide for further studies with other pollutants on several tissues in in vivo studies.

It is interesting to consider that these assessments can be applied to other environmental pollutants, which can be considered carcinogenic, to determine if they can be aligned to the several characteristics of human carcinogens described by the IARC. Thus, the study of EDC exposure and its effects on carcinogenesis is certainly necessary to augment scientific evidence in this regard and originate preventive action plans to improve the quality of life of future generations $(8,183)$. Despite several limitations in each study, the continuous investigation will allow properly cover those limitations one by one. Further analysis and data compilation will be a key issue in this process as well. Moreover, to grasp more details of such complex molecular-mechanisms present in the human body will help us to come up with more solid conclusions regarding the direct effect of endocrine disruptors on a specific process, especially carcinogenesis of breast cancer that indeed can be correlated with in vivo studies and epidemiological evidence (184). We hope that current and future knowledge will not be forsaken regarding most of the men-made compounds that are released into the environment. A study like this enables us to realize the real effects and hazards of these compounds and comprehend that wildlife, animals, and eventually humans will suffer the consequences. Small attempts from the scientific community have been made in order to clarify the real effects of these compounds on the human body $(8,185)$. Therefore, this can serve as a key for decisions regarding what pesticides or industrial compounds will be used in the future. The data, collected up to now is certainly not negligible and must be considered by governments, policymakers, and the industry. The knowledge about these pesticides does not only serve as an alert but also as a perspective-change, where the considerations of the development of future industrial material, manufacturing processes, material usage, waste release process, and other ones can be more friendly with health and environment.

Finally, scientists in order to purify or detoxify animals and the environment have prompted to search for new treatments or processes based on the new technology. Therefore, technologies as bio-nanotechnology can serve as an important tool in the treatment of detoxification of certain pollutants using different mechanisms and nano-materials (177), as the so-called nano-pesticides. They are intelligent nanoparticles that release the compound according to the needs of the environment improving not only the crops but also decreasing their amount in the soil, water, and air (186). The nano-micelle-based products are a nano-system able to entrap harmful particles from the environment, which are the main focus in the food industry due to their ability to clear away pesticides from vegetables (187). The same concept can probably be used to capture contaminants from the environment or from living organisms including human beings. Undoubtedly, these materials due to their physicochemical properties as their size, solubility, and transport capacity can be used to go further and to specific genes, being a challenge for future researchers. On the other hand, the study concerning the direct influence of EDCs on certain hormone-dependent cancers as breast, prostate, ovaries and testicular will provide new insights in the study of disruption of normal endocrine function that may cause long-term effects not only in initiation but also in cancer progression. Consequently, this work will set up a model for further analysis and classification of other EDCs.

\section{Acknowledgements}

The authors would like to thank Mr. Leodán A. Crispin (Instituto de Alta Investigación, Universidad de Tarapacá, Arica, Chile) for technical support.

\section{Funding}

The present study was supported by a grant from UTA-MINEDUC (grant no. UTA1117) and Fondo Nacional de Ciencias (FONDECYT) [grant no. 1200656 (GMC)].

\section{Availability of data and materials}

Not applicable.

\section{Authors' contributions}

GMC, RPC, FA, JPM and TCB wrote, edited and reviewed the manuscript, and agreed to be accountable for all aspects of the revision in ensuring that the accuracy or integrity of any part of the work was appropriately conducted. All authors read and approved the final manuscript.

\section{Ethics approval and consent to participate}

Not applicable.

\section{Patient consent for publication}

Not applicable.

\section{Competing interests}

The authors declare that they have no competing interests.

\section{References}

1. Thomas D: Gene-environment-wide association studies: Emerging approaches. Nat Rev Genet 11: 259-272, 2010.

2. Guyton KZ, Rieswijk L, Wang A, Chiu WA and Smith MT: Key characteristics approach to carcinogenic hazard identification. Chem Res Toxicol 31: 1290-1292, 2018.

3. IARC: Some organophosphate insecticides and herbicides. IARC Working Group on the Evaluation of Carcinogenic Risks to Humans. IARC Monographs 112: 464. 2017.

4. IARC: Table I. Key characteristics of carcinogens. Journal 1-5, 2014.

5. Diamanti-Kandarakis E, Palioura E, Kandarakis SA and Koutsilieris M: The impact of endocrine disruptors on endocrine targets. Horm Metab Res 42: 543-552, 2010.

6. Crews D and McLachlan JA: Epigenetics, evolution, endocrine disruption, health, and disease. Endocrinology 147 (Suppl 6): S4-S10, 2006.

7. Macon MB and Fenton SE: Endocrine disruptors and the breast: Early life effects and later life disease. J Mammary Gland Biol Neoplasia 18: 43-61, 2013.

8. Diamanti-Kandarakis E, Bourguignon JP, Giudice LC, Hauser R, Prins GS, Soto AM, Zoeller RT and Gore AC: Endocrine-disrupting chemicals: An Endocrine Society scientific statement. Endocr Rev 30: 293-342, 2009. 
9. Roy JR, Chakraborty S and Chakraborty TR: Estrogen-like endocrine disrupting chemicals affecting puberty in humans - a review. Med Sci Monit 15: RA137-RA145, 2009.

10. Davis DL, Bradlow HL, Wolff M, Woodruff T, Hoel DG and Anton-Culver H: Medical hypothesis: Xenoestrogens as preventable causes of breast cancer. Environ Health Perspect 101: 372-377, 1993.

11. Davis DL and Bradlow HL: Can environmental estrogens cause breast cancer? Sci Am 273: 167-172, 1995.

12. Hulka BS, Liu ET and Lininger RA: Steroid hormones and risk of breast cancer. Cancer 74 (Suppl 3): S1111-S1124, 1994.

13. Safe SH: Environmental and dietary estrogens and human health: Is there a problem? Environ Health Perspect 103: 346-351, 1995.

14. Anway MD and Skinner MK: Epigenetic transgenerational actions of endocrine disruptors. Endocrinology 147 (Suppl 6): S43-S49, 2006.

15. Anway MD and Skinner MK: Transgenerational effects of the endocrine disruptor vinclozolin on the prostate transcriptome and adult onset disease. Prostate 68: 517-529, 2008.

16. Anway MD, Cupp AS, Uzumcu M and Skinner MK: Epigenetic transgenerational actions of endocrine disruptors and male fertility. Science 308: 1466-1469, 2005

17. Christiansen S, Scholze M, Axelstad M, Boberg J, Kortenkamp A and Hass U: Combined exposure to anti-androgens causes markedly increased frequencies of hypospadias in the rat. Int J Androl 31: 241-248, 2008

18. Shono T, Suita S, Kai H and Yamaguchi Y: Short-time exposure to vinclozolin in utero induces testicular maldescent associated with a spinal nucleus alteration of the genitofemoral nerve in rats. J Pediatr Surg 39: 217-219; discussion 217-219, 2004

19. Monosson E, Kelce WR, Lambright C, Ostby J and Gray LE Jr: Peripubertal exposure to the antiandrogenic fungicide, vinclozolin, delays puberty, inhibits the development of androgen-dependent tissues, and alters androgen receptor function in the male rat. Toxicol Ind Health 15: 65-79, 1999.

20. Schug TT, Janesick A, Blumberg B and Heindel JJ: Endocrine disrupting chemicals and disease susceptibility. J Steroid Biochem Mol Biol 127: 204-215, 2011.

21. Staples CA, Dorn PB, Klecka GM, O'Block ST and Harris LR: A review of the environmental fate, effects, and exposures of bisphenol A. Chemosphere 36: 2149-2173, 1998

22. Calafat AM, Kuklenyik Z, Reidy JA, Caudill SP, Ekong J and Needham LL: Urinary concentrations of bisphenol A and 4-nonylphenol in a human reference population. Environ Health Perspect 113: 391-395, 2005.

23. Sengupta S, Obiorah I, Maximov PY, Curpan R and Jordan VC: Molecular mechanism of action of bisphenol and bisphenol A mediated by oestrogen receptor alpha in growth and apoptosis of breast cancer cells. Br J Pharmacol 169: 167-178, 2013.

24. Mlynarcikova A, Macho L and Fickova M: Bisphenol A alone or in combination with estradiol modulates cell cycle- and apoptosis-related proteins and genes in MCF7 cells. Endocr Regul 47: 189-199, 2013.

25. Katchy A, Pinto C, Jonsson P, Nguyen-Vu T, Pandelova $M$ Riu A, Schramm KW, Samarov D, Gustafsson JA, Bondesson M and Williams C: Coexposure to phytoestrogens and bisphenol A mimics estrogenic effects in an additive manner. Toxicol Sci 138 $21-35,2014$

26. Keri RA, Ho SM, Hunt PA, Knudsen KE, Soto AM and Prins GS: An evaluation of evidence for the carcinogenic activity of bisphenol A. Reprod Toxicol 24: 240-252, 2007.

27. Lamartiniere CA, Jenkins S, Betancourt AM, Wang J and Russo J: Exposure to the endocrine disruptor bisphenol A alters susceptibility for mammary cancer. Horm Mol Biol Clin Investig 5: 45-52, 2011.

28. Markey CM, Luque EH, Munoz De Toro M, Sonnenschein C and Soto AM: In utero exposure to bisphenol A alters the development and tissue organization of the mouse mammary gland. Biol Reprod 65: 1215-1223, 2001

29. Weber Lozada K and Keri RA: Bisphenol A increases mammary cancer risk in two distinct mouse models of breast cancer. Biol Reprod 85: 490-497, 2011.

30. Qin XY, Fukuda T, Yang L, Zaha H, Akanuma H, Zeng Q, Yoshinaga $\mathrm{J}$ and Sone $\mathrm{H}$ : Effects of bisphenol A exposure on the proliferation and senescence of normal human mammary epithelial cells. Cancer Biol Ther 13: 296-306, 2012.

31. Buterin T, Koch $\mathrm{C}$ and Naegeli H: Convergent transcriptional profiles induced by endogenous estrogen and distinct xenoestrogens in breast cancer cells. Carcinogenesis 27: 1567-1578, 2006
32. Moral R, Wang R, Russo IH, Lamartiniere CA, Pereira J and Russo J: Effect of prenatal exposure to the endocrine disruptor bisphenol A on mammary gland morphology and gene expression signature. J Endocrinol 196: 101-112, 2008.

33. Ptak A, Wrobel A and Gregoraszczuk EL: Effect of bisphenol-A on the expression of selected genes involved in cell cycle and apoptosis in the OVCAR-3 cell line. Toxicol Lett 202: 30-35, 2011.

34. Shafei A, Ramzy MM, Hegazy AI, Husseny AK, El-Hadary UG, Taha MM and Mosa AA: The molecular mechanisms of action of the endocrine disrupting chemical bisphenol A in the development of cancer. Gene 647: 235-243, 2018.

35. Muñoz-de-Toro M, Markey CM, Wadia PR, Luque EH, Rubin BS, Sonnenschein C and Soto AM: Perinatal exposure to bisphenol-A alters peripubertal mammary gland development in mice. Endocrinology 146: 4138-4147, 2005.

36. Russo J, Tait L and Russo IH: Susceptibility of the mammary gland to carcinogenesis. III. The cell of origin of rat mammary carcinoma. Am J Pathol 113: 50-66, 1983.

37. Hilakivi-Clarke L, Cho E, deAssis S, Olivo S, Ealley E, Bouker KB, Welch JN, Khan G, Clarke R and Cabanes A: Maternal and prepubertal diet, mammary development and breast cancer risk. J Nutr 131 (Suppl): S154-S157, 2001.

38. Birnbaum LS and Fenton SE: Cancer and developmental exposure to endocrine disruptors. Environ Health Perspect 111 389-394, 2003.

39. Russo $\mathbf{J}$ and Russo IH: Influence of differentiation and cell kinetics on the susceptibility of the rat mammary gland to carcinogenesis. Cancer Res 40: 2677-2687, 1980.

40. Tay LK and Russo J: Formation and removal of 7,12-dimethylbenz[a]anthracene-nucleic acid adducts in rat mammary epithelial cells with different susceptibility to carcinogenesis. Carcinogenesis 2: 1327-1333, 1981.

41. Russo IH, Koszalka M and Russo J: Comparative study of the influence of pregnancy and hormonal treatment on mammary carcinogenesis. Br J Cancer 64: 481-484, 1991.

42. Thordarson G, Jin E, Guzman RC, Swanson SM, Nandi S and Talamantes F: Refractoriness to mammary tumorigenesis in parous rats: Is it caused by persistent changes in the hormonal environment or permanent biochemical alterations in the mammary epithelia? Carcinogenesis 16: 2847-2853, 1995.

43. Sivaraman L and Medina D: Hormone-induced protection against breast cancer. J Mammary Gland Biol Neoplasia 7: 77-92, 2002.

44. Yang J, Yoshizawa K, Nandi S and Tsubura A: Protective effects of pregnancy and lactation against $\mathrm{N}$-methyl-N-nitrosourea-induced mammary carcinomas in female Lewis rats. Carcinogenesis 20: 623-628, 1999

45. Nandi S, Guzman RC, Thordarson G and Rajkumar L: Estrogen can prevent breast cancer by mimicking the protective effect of pregnancy. In: Hormonal Carcinogenesis IV. Li JJ, Li SA and Llombart-Bosch A (eds). Springer, New York, NY, pp153-165, 2005.

46. Hu YF, Russo IH, Zalipsky U, Lynch HT and Russo J: Environmental chemical carcinogens induce transformation of breast epithelial cells from women with familial history of breast cancer. In Vitro Cell Dev Biol Anim 33: 495-498, 1997.

47. Boylan ES and Calhoon RE: Mammary tumorigenesis in the rat following prenatal exposure to diethylstilbestrol and postnatal treatment with 7,12-dimethylbenz[a]anthracene. J Toxicol Environ Health 5: 1059-1071, 1979.

48. Lamartiniere CA and Holland MB: Neonatal diethylstilbestrol prevents spontaneously developing mammary tumors. Hormonal Carcinogenesis: 308-308, 1992.

49. Shellabarger CJ and Soo VA: Effects of neonatally administered sex steroids on 7,12-dimethylbenz(a)anthracene-induced mammary neoplasia in rats. Cancer Res 33: 1567-1569, 1973.

50. Nagasawa $H$, Yanai R, Shodono M, Nakamura T and Tanabe $Y$ : Effect of neonatally administered estrogen or prolactin on normal and neoplastic mammary growth and serum estradiol-17 beta level in rats. Cancer Res 34: 2643-2646, 1974

51. FDA: Bisphenol A (BPA): Use in food contact application. https://www.fda.gov/food/food-additives-petitions/bisphenolbpa-use-food-contact-application. Accessed July, 2019.

52. Kovacic P: How safe is bisphenol A? Fundamentals of toxicity: Metabolism, electron transfer and oxidative stress. Med Hypotheses 75: 1-4, 2010.

53. Vafa O, Wade M, Kern S, Beeche M, Pandita TK, Hampton GM and Wahl GM: c-Myc can induce DNA damage, increase reactive oxygen species, and mitigate p53 function: A mechanism for oncogene-induced genetic instability. Mol Cell 9: 1031-1044, 2002. 
54. Pfeifer D, Chung YM and Hu MC: Effects of low-dose bisphenol A on DNA damage and proliferation of breast cells: The role of c-Myc. Environ Health Perspect 123: 1271-1279, 2015

55. Olsen CM, Meussen-Elholm ET, Samuelsen M, Holme JA and Hongslo JK: Effects of the environmental oestrogens bisphenol A, tetrachlorobisphenol A, tetrabromobisphenol A, 4-hydroxybiphenyl and 4,4'-dihydroxybiphenyl on oestrogen receptor binding, cell proliferation and regulation of oestrogen sensitive proteins in the human breast cancer cell line MCF-7. Pharmacol Toxicol 92: 180-188, 2003.

56. Liu Y, Qu K, Hai Y and Zhao C: Bisphenol A (BPA) binding on full-length architectures of estrogen receptor. J Cell Biochem 119: 6784-6794, 2018.

57. Kim JY, Choi HG, Lee HM, Lee GA, Hwang KA and Choi KC: Effects of bisphenol compounds on the growth and epithelial mesenchymal transition of MCF-7 CV human breast cancer cells J Biomed Res 31: 358-369, 2017.

58. Routledge EJ, White R, Parker MG and Sumpter JP: Differential effects of xenoestrogens on coactivator recruitment by estrogen receptor (ER) alpha and ERbeta. J Biol Chem 275: 35986-35993, 2000.

59. Matthews JB, Twomey $\mathrm{K}$ and Zacharewski TR: In vitro and in vivo interactions of bisphenol $\mathrm{A}$ and its metabolite, bisphenol $\mathrm{A}$ glucuronide, with estrogen receptors alpha and beta. Chem Res Toxicol 14: 149-157, 2001.

60. Singh M, McGinley JN and Thompson HJ: A comparison of the histopathology of premalignant and malignant mammary gland lesions induced in sexually immature rats with those occurring in the human. Lab Invest 80: 221-231, 2000.

61. Murray TJ, Maffini MV, Ucci AA, Sonnenschein C and Soto AM: Induction of mammary gland ductal hyperplasias and carcinoma in situ following fetal bisphenol A exposure. Reprod Toxicol 23 383-390, 2007.

62. Rochester JR: Bisphenol A and human health: A review of the literature. Reprod Toxicol 42: 132-155, 2013.

63. Rogers JA, Metz L and Yong VW: Review: Endocrine disrupting chemicals and immune responses: A focus on bisphenol-A and its potential mechanisms. Mol Immunol 53: 421-430, 2013.

64. Liao SL, Tsai MH, Lai SH, Yao TC, Hua MC, Yeh KW, Chiang CH, Huang SY and Huang JL: Prenatal exposure to bisphenol-A is associated with Toll-like receptor-induced cytokine suppression in neonates. Pediatr Res 79: 438-444, 2016.

65. Parker LC, Prince LR and Sabroe I: Translational mini-review series on Toll-like receptors: Networks regulated by Toll-like receptors mediate innate and adaptive immunity. Clin Exp Immunol 147: 199-207, 2007.

66. Deblois $\mathrm{G}$ and Giguère V: Functional and physiological genomics of estrogen-related receptors (ERRs) in health and disease. Biochim Biophys Acta 1812: 1032-1040, 2011.

67. Salem ML: Estrogen, a double-edged sword: Modulation of TH1and $\mathrm{TH} 2$-mediated inflammations by differential regulation of TH1/TH2 cytokine production. Curr Drug Targets Inflamm Allergy 3: 97-104, 2004.

68. Xu J, Huang G and Guo TL: Developmental bisphenol A exposure modulates immune-related diseases. Toxics 4: E23, 2016.

69. Picard D: Molecular mechanisms of cross-talk between growth factors and nuclear receptor signaling. Pure App Chem 75: 1743-1756, 2003

70. Saavedra HI, Fukasawa K, Conn CW and Stambrook PJ: MAPK mediates RAS-induced chromosome instability. J Biol Chem 274: 38083-38090, 1999.

71. Li X, Zhang S and Safe S: Activation of kinase pathways in MCF-7 cells by 17beta-estradiol and structurally diverse estrogenic compounds. J Steroid Biochem Mol Biol 98: 122-132, 2006.

72. Ho SM, Tang WY, Belmonte de Frausto $J$ and Prins GS: Developmental exposure to estradiol and bisphenol A increases susceptibility to prostate carcinogenesis and epigenetically regulates phosphodiesterase type 4 variant 4 . Cancer Res 66 : 5624-5632, 2006.

73. Prins GS, Tang WY, Belmonte J and Ho SM: Developmental exposure to bisphenol A increases prostate cancer susceptibility in adult rats: Epigenetic mode of action is implicated. Fertil Steril 89 (Suppl 2): e41, 2008.

74. Weng YI, Hsu PY, Liyanarachchi S, Liu J, Deatherage DE, Huang YW, Zuo T, Rodriguez B, Lin CH, Cheng AL and Huang TH: Epigenetic influences of low-dose bisphenol A in primary human breast epithelial cells. Toxicol Appl Pharmacol 248: 111-121, 2010.

75. Xin F, Susiarjo M and Bartolomei MS: Multigenerational and transgenerational effects of endocrine disrupting chemicals: A role for altered epigenetic regulation? Semin Cell Dev Biol 43: 66-75, 2015.
76. Kundakovic $M$ and Champagne FA: Epigenetic perspective on the developmental effects of bisphenol A. Brain Behav Immun 25: 1084-1093, 2011.

77. Mileva G, Baker SL, Konkle AT and Bielajew C: Bisphenol-A: epigenetic reprogramming and effects on reproduction and behavior. Int J Environ Res Public Health 11: 7537-7561, 2014.

78. Morgan HD, Sutherland HG, Martin DI and Whitelaw E: Epigenetic inheritance at the agouti locus in the mouse. Nat Genet 23: 314-318, 1999.

79. Dolinoy DC, Huang D and Jirtle RL: Maternal nutrient supplementation counteracts bisphenol A-induced DNA hypomethylation in early development. Proc Natl Acad Sci USA 104: 13056-13061, 2007.

80. Doherty LF, Bromer JG, Zhou Y, Aldad TS and Taylor HS: In utero exposure to diethylstilbestrol (DES) or bisphenol-A (BPA) increases EZH2 expression in the mammary gland: An epigenetic mechanism linking endocrine disruptors to breast cancer. Horm Cancer 1: 146-155, 2010.

81. Dhimolea E, Wadia PR, Murray TJ, Settles ML, Treitman JD, Sonnenschein C, Shioda T and Soto AM: Prenatal exposure to BPA alters the epigenome of the rat mammary gland and increases the propensity to neoplastic development. PLoS One 9: e99800, 2014.

82. Loft S, Fischer-Nielsen A, Jeding IB, Vistisen K and Poulsen HE: 8-Hydroxydeoxyguanosine as a urinary biomarker of oxidative DNA damage. J Toxicol Environ Health 40: 391-404, 1993.

83. Kasai $\mathrm{H}$ : Analysis of a form of oxidative DNA damage, 8-hydroxy-2'-deoxyguanosine, as a marker of cellular oxidative stress during carcinogenesis. Mutat Res 387: 147-163, 1997.

84. Sabu A and Jain N: Bisphenol A induced oxidative stress and the biochemical profile: An in vitro approach. European J Biotechnol Biosci 6: 21-24, 2018.

85. Acconcia F, Pallottini V and Marino M: Molecular Mechanisms of Action of BPA. Dose Response 13: 1559325815610582, 2015.

86. Li L, Wang Q, Zhang Y, Niu Y, Yao X and Liu H: The molecular mechanism of bisphenol A (BPA) as an endocrine disruptor by interacting with nuclear receptors: Insights from molecular dynamics (MD) simulations. PLoS One 10: e0120330, 2015.

87. Vandenberg LN, Colborn T, Hayes TB, Heindel JJ, Jacobs DR Jr, Lee DH, Shioda T, Soto AM, vom Saal FS, Welshons WV, et al: Hormones and endocrine-disrupting chemicals: Low-dose effects and nonmonotonic dose responses. Endocr Rev 33: 378-455, 2012.

88. ATSDR: Toxicological profile for DDT, DDE, and DDD. https:// www.atsdr.cdc.gov/ToxProfiles/tp.asp?id=81\&tid=20. Accessed September, 2018.

89. CDC: Dichlorodiphenyltrichloroethane (DDT). https://www.cdc. gov/biomonitoring/DDT_FactSheet.html. Accessed July, 2018.

90. Wolff MS: Half-lives of organochlorines (OCs) in humans. Arch Environ Contam Toxicol 36: 504, 1999.

91. Waliszewski SM, Melo-Santiesteban G, Villalobos-Pietrini R, Gómez-Arroyo S, Amador-Muñoz O, Herrero-Mercado M and Carvajal O: Breast milk excretion Kinetic of b-HCH, pp'DDE and pp'DDT. Bull Environ Contam Toxicol 83: 869-873, 2009.

92. Lim JS, Son HK, Park SK, Jacobs DR Jr and Lee DH: Inverse associations between long-term weight change and serum concentrations of persistent organic pollutants. Int J Obes (Lond) 35: 744-747, 2011.

93. Elobeid MA, Padilla MA, Brock DW, Ruden DM and Allison DB: Endocrine disruptors and obesity: An examination of selected persistent organic pollutants in the NHANES 1999-2002 data. Int J Environ Res Public Health 7: 2988-3005, 2010.

94. Everett CJ, Frithsen IL, Diaz VA, Koopman RJ, Simpson WM Jr and Mainous AG III: Association of a polychlorinated dibenzo-p-dioxin, a polychlorinated biphenyl, and DDT with diabetes in the 1999-2002 National Health and Nutrition Examination Survey. Environ Res 103: 413-418, 2007.

95. Beard J and Australian Rural Health Research Collaboration: DDT and human health. Sci Total Environ 355: 78-89, 2006.

96. Kelce WR, Stone CR, Laws SC, Gray LE, Kemppainen JA and Wilson EM: Persistent DDT metabolite p,p'-DDE is a potent androgen receptor antagonist. Nature 375: 581-585, 1995.

97. Steinmetz R, Young PC, Caperell-Grant A, Gize EA, Madhukar BV, Ben-Jonathan N and Bigsby RM: Novel estrogenic action of the pesticide residue beta-hexachlorocyclohexane in human breast cancer cells. Cancer Res 56: 5403-5409, 1996.

98. Lemaire G, Mnif W, Mauvais P, Balaguer P and Rahmani R: Activation of alpha- and beta-estrogen receptors by persistent pesticides in reporter cell lines. Life Sci 79: 1160-1169, 2006.

99. Pestana D, Teixeira D, Faria A, Domingues V, Monteiro R and Calhau C: Effects of environmental organochlorine pesticides on human breast cancer: Putative involvement on invasive cell ability. Environ Toxicol 30: 168-176, 2015. 
100. Fenga C: Occupational exposure and risk of breast cancer. Biomed Rep 4: 282-292, 2016.

101. Lessa JM, Beçak W, Nazareth Rabello M, Pereira CA and Ungaro MT: Cytogenetic study of DDT on human lymphocytes in vitro. Mutat Res 40: 131-138, 1976.

102. Amer SM, Fahmy MA and Donya SM: Cytogenetic effect of some insecticides in mouse spleen. J Appl Toxicol 16: 1-3, 1996.

103. Andersen HR, Andersson AM, Arnold SF, Autrup H, Barfoed M, Beresford NA, Bjerregaard P, Christiansen LB, Gissel B, Hummel R, et al: Comparison of short-term estrogenicity tests for identification of hormone-disrupting chemicals. Environ Health Perspect 107 (Suppl 1): S89-S108, 1999.

104. Bulger WH and Kupfer D: Estrogenic action of DDT analogs Am J Ind Med 4: 163-173, 1983.

105. Dees C, Askari M, Foster JS, Ahamed S and Wimalasena J: DDT mimicks estradiol stimulation of breast cancer cells to enter the cell cycle. Mol Carcinog 18: 107-114, 1997.

106. Lin ZX, Kavanagh T, Trosko JE and Chang CC: Inhibition of gap junctional intercellular communication in human teratocarcinoma cells by organochlorine pesticides. Toxicol App Pharmacol 83: 10-19, 1986.

107. Scribner JD and Mottet NK: DDT acceleration of mammary gland tumors induced in the male Sprague-Dawley rat by 2-acetamidophenanthrene. Carcinogenesis 2: 1235-1239, 1981.

108. Jaga K: What are the implications of the interaction between DDT and estrogen receptors in the body? Med Hypotheses 54 $18-25,2000$

109. Anand M, Singh J, Siddiqui MKJ, Taneja A, Patel DK and Mehrotra PK: Organochlorine pesticides in the females suffering from breast cancer and its relation to estrogen receptor status. J Drug Metab Toxicol 4: 156, 2013.

110. Dees C, Askari M, Garrett S, Gehrs K, Henley D and Ardies CM: Estrogenic and DNA-damaging activity of Red No. 3 in human breast cancer cells. Environ Health Perspect 105 (Suppl 3) S625-S632, 1997.

111. Dewailly E, Dodin S, Verreault R, Ayotte P, Sauvé L, Morin J and Brisson J: High organochlorine body burden in women with estrogen receptor-positive breast cancer. J Natl Cancer Inst 86 232-234, 1994.

112. Anderson LF: DDT and breast cancer: The verdict isn't in. J Natl Cancer Inst 86: 576-577, 1994

113. Krieger N, Wolff MS, Hiatt RA, Rivera M, Vogelman J and Orentreich N: Breast cancer and serum organochlorines: A prospective study among white, black, and Asian women. J Nat Cancer Inst 86: 589-599, 1994

114. Street JC and Sharma RP: Alteration of induced cellular and humoral immune responses by pesticides and chemicals of environmental concern: Quantitative studies of immunosuppression by DDT, aroclor 1254, carbaryl, carbofuran, and methylparathion. Toxicol Appl Pharmacol 32: 587-602, 1975.

115. Gourounti K and Andreas L: Burden of organochlorine substances as a risk factor of breast cancer. Health Sci J 3: 19-31, 2009.

116. Vineis $\mathrm{P}$ and D'Amore $\mathrm{F}$ : The role of occupational exposure and immunodeficiency in B-cell malignancies. Working Group on the Epidemiology of Hematolymphopoietic Malignancies in Italy. Epidemiology 3: 266-270, 1992.

117. Handy DE, Castro R and Loscalzo J: Epigenetic modifications: Basic mechanisms and role in cardiovascular disease. Circulation 123: 2145-2156, 2011.

118. Chuang JC and Jones PA: Epigenetics and microRNAs. Pediatr Res 61: 24R-29R, 2007.

119. Shutoh Y, Takeda M, Ohtsuka R, Haishima A, Yamaguchi S, Fujie H, Komatsu Y, Maita K and Harada T: Low dose effects of dichlorodiphenyltrichloroethane (DDT) on gene transcription and DNA methylation in the hypothalamus of young male rats: Implication of hormesis-like effects. J Toxicol Sci 34: 469-482, 2009.

120. Skinner MK, Manikkam M, Tracey R, Guerrero-Bosagna C, Haque $\mathrm{M}$ and Nilsson EE: Ancestral dichlorodiphenyltrichloroethane (DDT) exposure promotes epigenetic transgenerational inheritance of obesity. BMC Med 11: 228, 2013.

121. Gulyaeva LF, Chanyshev MD, Kolmykov SK, Ushakov DS and Nechkin SS: The effect of xenobiotics on microRNA expression in the rat liver. Biochem Moscow Suppl Ser B 10: 258-263, 2016.

122. Parke DV, Ioannides C and Lewis DF: The 1990 pharmaceutical manufacturers association of Canada keynote lecture. The role of the cytochromes P450 in the detoxication and activation of drugs and other chemicals. Can J Physiol Pharmacol 69: 537-549, 1991.
123. Pal R, Ahmed T, Kumar V, Suke SG, Ray A and Banerjee BD Protective effects of different antioxidants against endosulfan-induced oxidative stress and immunotoxicity in albino rats. Indian J Exp Biol 47: 723-729, 2009.

124. Iscan M, Coban T, Cok I, Bulbul D, Eke BC and Burgaz S The organochlorine pesticide residues and antioxidant enzyme activities in human breast tumors: Is there any association? Breast Cancer Res Treat 72: 173-182, 2002.

125. Al-Gubory KH: Environmental pollutants and lifestyle factors induce oxidative stress and poor prenatal development. Reprod Biomed Online 29: 17-31, 2014.

126. Sahoo A, Samanta L and Chainy GB: Mediation of oxidative stress in $\mathrm{HCH}$-induced neurotoxicity in rat. Arch Environ Contam Toxicol 39: 7-12, 2000.

127. Kostka G, Palut D and Wiadrowska B: The effect of permethrin and DDT on the activity of cytochrome P-450 1A and 2B molecular forms in rat liver. Rocz Panstw Zakl Hig 48: 229-237, 1997 (In Polish).

128. Ames BN, Gold LS and Willett WC: The causes and prevention of cancer. Proc Natl Acad Sci USA 92: 5258-5265, 1995.

129. Canales-Aguirre A, Padilla-Camberos E, Gómez-Pinedo U, Salado-Ponce H, Feria-Velasco A and De Celis R: Genotoxic effect of chronic exposure to DDT on lymphocytes, oral mucosa and breast cells of female rats. Int J Environ Res Public Health 8: 540-553, 2011.

130. Harada T, Takeda M, Kojima S and Tomiyama N: Toxicity and Carcinogenicity of Dichlorodiphenyltrichloroethane (DDT) Toxicol Res 32: 21-33, 2016.

131. Kim JY, Choi CY, Lee KJ, Shin DW, Jung KS, Chung YC, Lee SS, Shin JG and Jeong HG: Induction of inducible nitric oxide synthase and proinflammatory cytokines expression by o,p'-DDT in macrophages. Toxicol Lett 147: 261-269, 2004

132. Zhang YQ, Mao Z, Zheng YL, Han BP, Chen LT, Li J and Li F: Elevation of inducible nitric oxide synthase and cyclooxygenase-2 expression in the mouse brain after chronic nonylphenol exposure. Int J Mol Sci 9: 1977-1988, 2008.

133. Alegria-Torres JA, Díaz-Barriga F, Gandolfi AJ and Pérez-Maldonado IN: Mechanisms of p,p'-DDE-induced apoptosis in human peripheral blood mononuclear cells. Toxicol In Vitro 23: 1000-1006, 2009.

134. Wolff MS, Toniolo PG, Lee EW, Rivera M and Dubin N: Blood levels of organochlorine residues and risk of breast cancer. J Natl Cancer Inst 85: 648-652, 1993.

135. IARC Working Group on the Evaluation of Carcinogenic Risk to Humans: DDT, Lindane, and 2,4-D. IARC Monographs 113: 513, 2018

136. EPA: PCBs: Cancer dose-response assessment and application to environmental mixtures. https://cfpub.epa.gov/si/si_public_ record_report.cfm?Lab $=$ NCEA \&TIMSType $=\&$ count $=10000$ $\&$ dirEntryId=12486\&searchAll=\&showCriteria $=2 \&$ simpleSe $\operatorname{arch}=0$. Accessed October, 2018.

137. EPA: Polychlorinated Biphenyls (PCBs). https://www.epa.gov/ pcbs. Accessed July, 2018.

138. Ravenscroft J, Schell LM and Akwesasne Task Force on the Environ Int: Patterns of PCB exposure among Akwesasne adolescents: The role of dietary and inhalation pathways. Environ Int 121: 963-972, 2018.

139. Petreas M, Nelson D, Brown FR, Goldberg D, Hurley S and Reynolds P: High concentrations of polybrominated diphenylethers (PBDEs) in breast adipose tissue of California women Environ Int 37: 190-197, 2011

140. Faroon O and Ruiz P: Polychlorinated biphenyls: New evidence from the last decade. Toxicol Ind Health 32: 1825-1847, 2016.

141. Ellsworth RE, Mamula KA, Costantino NS, Deyarmin B, Kostyniak PJ, Chi LH, Shriver CD and Ellsworth DL: Abundance and distribution of polychlorinated biphenyls (PCBs) in breast tissue. Environ Res 138: 291-297, 2015.

142. Zhang J, Huang Y, Wang X, Lin K and Wu K: Environmental polychlorinated biphenyl exposure and breast cancer risk: A meta-analysis of observational studies. PLoS One 10: e0142513, 2015

143. Demers A, Ayotte P, Brisson J, Dodin S, Robert J and Dewailly E: Risk and aggressiveness of breast cancer in relation to plasma organochlorine concentrations. Cancer Epidemiol Biomarkers Prev 9: 161-166, 2000.

144. Ritter R, Scheringer M, MacLeod M, Moeckel C, Jones KC and Hungerbühler K: Intrinsic human elimination half-lives of polychlorinated biphenyls derived from the temporal evolution of cross-sectional biomonitoring data from the United Kingdom. Environ Health Perspect 119: 225-231, 2011.

145. Takeuchi S, Anezaki K and Kojima H: Effects of unintentional PCBs in pigments and chemical products on transcriptional activity via aryl hydrocarbon and nuclear hormone receptors. Environ Pollut 227: 306-313, 2017. 
146. Moysich KB, Shields PG, Freudenheim JL, Schisterman EF, Vena JE, Kostyniak P, Greizerstein H, Marshall JR, Graham S and Ambrosone CB: Polychlorinated biphenyls, cytochrome P4501A1 polymorphism, and postmenopausal breast cancer risk. Cancer Epidemiol Biomarkers Prev 8: 41-44, 1999.

147. Hopf NB, Ruder AM and Succop P: Background levels of polychlorinated biphenyls in the U.S. population. Sci Total Environ 407: 6109-6119, 2009.

148. Lauby-Secretan B, Loomis D, Grosse Y, El Ghissassi F, Bouvard V, Benbrahim-Tallaa L, Guha N, Baan R, Mattock H and Straif K; WHO International Agency for Research on Cancer: Carcinogenicity of polychlorinated biphenyls and polybrominated biphenyls. Lancet Oncol 14: 287-288, 2013.

149. McGovern V: PCBs are endocrine disruptors: Mixture affects reproductive development in female mice. Environ Health Perspect 114: 368-369, 2006.

150. Yang O, Kim HL, Weon JI and Seo YR: Endocrine-disrupting chemicals: Review of toxicological mechanisms using molecular pathway analysis. J Cancer Prev 20: 12-24, 2015.

151. Gregoraszczuk EL, Rak A, Ludewig G and Gasinska A: Effects of estradiol, PCB3, and their hydroxylated metabolites on proliferation, cell cycle, and apoptosis of human breast cancer cells Environ Toxicol Pharmacol 25: 227-233, 2008.

152. Robertson LW and Ludewig G: Polychlorinated Biphenyl (PCB) carcinogenicity with special emphasis on airborne PCBs. Gefahrst Reinhalt Luft 71: 25-32, 2011.

153. Espandiari P, Glauert HP, Lehmler HJ, Lee EY, Srinivasan C and Robertson LW: Polychlorinated biphenyls as initiators in liver carcinogenesis: Resistant hepatocyte model. Toxicol Appl Pharmacol 186: 55-62, 2003.

154. Parada H Jr, Wolff MS, Engel LS, Eng SM, Khankari NK, Neugut AI, Teitelbaum SL and Gammon MD: Polychlorinated biphenyls and their association with survival following breast cancer. Eur J Cancer 56: 21-30, 2016.

155. Silberhorn EM, Glauert HP and Robertson LW: Carcinogenicity of polyhalogenated biphenyls: PCBs and PBBs. Crit Rev Toxicol 20: 440-496, 1990.

156. McLean MR, Robertson LW and Gupta RC: Detection of PCB adducts by the ${ }^{32} \mathrm{P}$-postlabeling technique. Chem Res Toxicol 9 : $165-171,1996$

157. Oakley GG, Robertson LW and Gupta RC: Analysis of polychlorinated biphenyl-DNA adducts by ${ }^{32} \mathrm{P}$-postlabeling. Carcinogenesis 17: 109-114, 1996.

158. Ludewig G and Robertson LW: Polychlorinated biphenyls (PCBs) as initiating agents in hepatocellular carcinoma. Cance Lett 334: 46-55, 2013.

159. Nutter LM, Ngo EO and Abul-Hajj YJ: Characterization of DNA damage induced by 3,4-estrone-o-quinone in human cells. J Biol Chem 266: 16380-16386, 1991

160. Knower KC, To SQ, Leung YK, Ho SM and Clyne CD Endocrine disruption of the epigenome: A breast cancer link. Endocr Relat Cancer 21: T33-T55, 2014.

161. Casati L, Sendra R, Colciago A, Negri-Cesi P, Berdasco M, Esteller $\mathrm{M}$ and Celotti F: Polychlorinated biphenyls affect histone modification pattern in early development of rats: A role for androgen receptor-dependent modulation? Epigenomics 4: 101-112, 2012.

162. Desaulniers D, Xiao GH, Lian H, Feng YL, Zhu J, Nakai J and Bowers WJ: Effects of mixtures of polychlorinated biphenyls, methylmercury, and organochlorine pesticides on hepatic DNA methylation in prepubertal female Sprague-Dawley rats. Int J Toxicol 28: 294-307, 2009.

163. Fraga MF, Ballestar E, Villar-Garea A, Boix-Chornet M, Espada J, Schotta G, Bonaldi T, Haydon C, Ropero S, Petrie K, et al: Loss of acetylation at Lys16 and trimethylation at Lys 20 of histone $\mathrm{H} 4$ is a common hallmark of human cancer. Nat Genet 37: 391-400, 2005.

164. Kim KY, Kim DS, Lee SK, Lee IK, Kang JH, Chang YS, Jacobs DR, Steffes M and Lee DH: Association of low-dose exposure to persistent organic pollutants with global DNA hypomethylation in healthy Koreans. Environ Health Perspect 118: 370-374, 2010

165. Srinivasan A, Lehmler HJ, Robertson LW and Ludewig G: Production of DNA strand breaks in vitro and reactive oxygen species in vitro and in HL-60 cells by PCB metabolites. Toxicol Sci 60: 92-102, 2001

166. Dreiem A, Rykken S, Lehmler HJ, Robertson LW and Fonnum F: Hydroxylated polychlorinated biphenyls increase reactive oxygen species formation and induce cell death in cultured cerebellar granule cells. Toxicol Appl Pharmacol 240: 306-313, 2009.

167. Liehr JG and Roy D: Free radical generation by redox cycling of estrogens. Free Radic Biol Med 8: 415-423, 1990.
168. Han X and Liehr JG: DNA single-strand breaks in kidneys of Syrian hamsters treated with steroidal estrogens Hormone-induced free radical damage preceding renal malignancy. Carcinogenesis 15: 997-1000, 1994.

169. Liu S, Li S and Du Y: Polychlorinated biphenyls (PCBs) enhance metastatic properties of breast cancer cells by activating Rho-associated kinase (ROCK). PLoS One 5: e11272, 2010.

170. Nutter LM, Wu YY, Ngo EO, Sierra EE, Gutierrez PL and Abul-Hajj YJ: An o-quinone form of estrogen produces free radicals in human breast cancer cells: Correlation with DNA damage. Chem Res Toxicol 7: 23-28, 1994.

171. Han X and Liehr JG: Microsome-mediated 8-hydroxylation of guanine bases of DNA by steroid estrogens: Correlation of DNA damage by free radicals with metabolic activation to quinones. Carcinogenesis 16: 2571-2574, 1995.

172. Han X and Liehr JG: 8-Hydroxylation of guanine bases in kidney and liver DNA of hamsters treated with estradiol: Role of free radicals in estrogen-induced carcinogenesis. Cancer Res 54: 5515-5517, 1994

173. Lin $\mathrm{CH}$ and Lin P: Induction of imbalances in gene expression, oxidative DNA damage, and cell toxicity by a planar (PCB126) and a non-planar (PCB153) polychlorinated biphenyl congeners in human breast carcinoma cell lines. AACR 65: 280-281, 2005.

174. Kimbrough RD: Human health effects of polychlorinated biphenyls (PCBs) and polybrominated biphenyls (PBBs). Annu Rev Pharmacol Toxicol 27: 87-111, 1987.

175. Selgrade MK: Immunotoxicity: The risk is real. Toxicol Sci 100: 328-332, 2007

176. Ward MH, Colt JS, Metayer C, Gunier RB, Lubin J, Crouse V, Nishioka MG, Reynolds P and Buffler PA: Residential exposure to polychlorinated biphenyls and organochlorine pesticides and risk of childhood leukemia. Environ Health Perspect 117: 1007-1013, 2009.

177. Gupta P, Thompson BL, Wahlang B, Jordan CT, Zach Hilt J, Hennig B and Dziubla T: The environmental pollutant, polychlorinated biphenyls, and cardiovascular disease: A potential target for antioxidant nanotherapeutics. Drug Deliv Trans Res 8: 740-759, 2018.

178. Petriello MC, Hoffman JB, Vsevolozhskaya O, Morris AJ and Hennig B: Dioxin-like PCB 126 increases intestinal inflammation and disrupts gut microbiota and metabolic homeostasis. Environ Pollut 242: 1022-1032, 2018

179. Coxon T, Goldstein L and Odhiambo BK: Analysis of spatial distribution of trace metals, $\mathrm{PCB}$, and $\mathrm{PAH}$ and their potential impact on human health in Virginian Counties and independent cities, USA. Environ Geochem Health 41: 783-801, 2019.

180. IARC: Polychlorinated biphenyls and polybrominated biphenyls. Journal Volume 107: 510, 2016.

181. Safe SH: Modulation of gene expression and endocrine response pathways by $2,3,7,8$-tetrachlorodibenzo-p-dioxin and related compounds. Pharmacol Ther 67: 247-281, 1995.

182. Falck F Jr, Ricci A Jr, Wolff MS, Godbold J and Deckers P Pesticides and polychlorinated biphenyl residues in human breast lipids and their relation to breast cancer. Arch Environ Health 47: 143-146, 1992

183. Soto AM and Sonnenschein C: Environmental causes of cancer: Endocrine disruptors as carcinogens. Nat Rev Endocrinol 6: 363-370, 2010

184. Gore AC, Chappell VA, Fenton SE, Flaws JA, Nadal A, Prins GS, Toppari J and Zoeller RT: EDC-2: The Endocrine Society's second scientific statement on endocrine-disrupting chemicals. Endocr Rev 36: E1-E150, 2015.

185. Vandenberg LN, Colborn T, Hayes TB, Heindel JJ, Jacobs DR Jr, Lee DH, Myers JP, ShiodaT, Soto AM, vom SaalFS, et al: Regulatory decisions on endocrine disrupting chemicals should be based on the principles of endocrinology. Reprod Toxicol 38: 1-15, 2013.

186. Huang B, Chen F, Shen Y, Qian K, Wang Y, Sun C, Zhao X, Cui B, Gao F, Zeng Z and Cui H: Advances in targeted pesticides with environmentally responsive controlled release by nanotechnology. Nanomaterials (Basel) 8: E102, 2018.

187. Peters R, Bouwmeester H, Gottardo S, Amenta V, Arena M, Brandhoff P, Marvin HJ, Mech A, Moniz FB, Pesudo LQ, et al: Nanomaterials for products and application in agriculture, feed and food. Trends Food Sci Technol 54: 155-164, 2016.

This work is licensed under a Creative Commons Attribution-NonCommercial-NoDerivatives 4.0 International (CC BY-NC-ND 4.0) License. 